Check for updates

Cite this: Mater. Adv., 2021, 2, 336

Received 5th August 2020, Accepted 15th November 2020

DOI: 10.1039/d0ma00571a

rsc.li/materials-advances

\section{Ultrafine multi-metallic carbide nanocrystals encased in a carbon matrix as durable electrocatalysts towards effective alkaline hydrogen evolution reaction $\dagger$}

\author{
Zhao Wei,,$^{\mathrm{a}}$ Jingman Pang, $\neq^{\mathrm{b}}$ Yuan Ji, ${ }^{\mathrm{cd}}$ Xing Yang, ${ }^{a}$ Yundan Liu, ${ }^{* \mathrm{~cd}}$ Long Ren ${ }^{\mathrm{e}}$ and \\ Yun Zhang (D) *a
}

\begin{abstract}
Durable electrolytic hydrogen production at high-current densities $\left(>500 \mathrm{~mA} \mathrm{~cm}{ }^{-2}\right.$ ) is required as the basis of industrial scale hydrogen evolution reaction (HER). Electrocatalysts, with the purpose of accelerating HER, however, are far from meeting the requirements of high activity, cost effectiveness, and long-term stability, especially in alkaline media. Herein, a series of ultrafine bi- or tri-metallic Mobased carbides embedded in a graphitic carbon matrix are synthesized by a direct solid reaction between metal molybdate and dicyandiamide (DCA). The components of the proposed multi-metallic carbides can be controlled in a facile manner by precisely configuring the molybdates with different metal cations, enabling the design of electrocatalysts with optimized active sites for HER. With the carbon layer protecting against corrosion, the as-prepared series of $\left(\mathrm{Ni}_{x} \mathrm{CO}_{1-x}\right)_{6} \mathrm{MO}_{6} \mathrm{C}_{2}$ carbides presents effective HER performance, in which the optimized stoichiometric sample $\left(\left(\mathrm{Ni}_{0.2} \mathrm{CO}_{0.8}\right)_{6} \mathrm{MO}_{6} \mathrm{C}_{2}\right)$ requires an overpotential of $100 \mathrm{mV}$ to drive $10 \mathrm{~mA} \mathrm{~cm}{ }^{-2}$ current density for HER. With this electrocatalyst, a durable current density of $1000 \mathrm{~mA} \mathrm{~cm}{ }^{-2}$ can be achieved by applying an overpotential of $1.84 \mathrm{~V}$ towards HER, which is even lower than the required potential of the $\mathrm{Pt} / \mathrm{C}$ commercial electrocatalyst $(2.12 \mathrm{~V})$ for the same current density.
\end{abstract}

\section{Introduction}

To meet the increasing global energy demand and decelerate the growing pollutant emissions, exploring green energy sources to replace fossil fuels has become a major challenge. As a renewable clean energy with high calorific value, ${ }^{1}$ hydrogen energy has received extensive attention from academia and

\footnotetext{
${ }^{a}$ School of Physics and Opto-Electronic Technology, Collaborative Innovation Center of Rare-Earth Optical Functional Materials and Devices Development, Baoji University of Arts and Sciences, Baoji, Shaanxi, 721016, P. R. China. E-mail: zhangyun_xtu@163.com

${ }^{b}$ Department of Chemistry and Chemical Engineering, Baoji University of Arts and Science, Baoji 721016, China

${ }^{c}$ Hunan Key Laboratory of Micro-Nano Energy Materials and Devices, Xiangtan University, Hunan 411105, P. R. China. E-mail: liuyd@xtu.edu.cn

${ }^{d}$ Laboratory for Quantum Engineering and Micro-Nano Energy Technology and Faculty of Materials and Optoelectronic Physics, Xiangtan University, Hunan 411105, P. R. China

${ }^{e}$ Institute for Superconducting and Electronic Materials (ISEM), Australian Institute for Innovative Materials (AIIM), University of Wollongong, Wollongong, NSW, 2500, Australia

$\dagger$ Electronic supplementary information (ESI) available. See DOI: 10.1039/ d0ma00571a

\# These authors contributed equally.
}

industry. At present, hydrogen production methods mainly include biological hydrogen production, fossil fuel hydrogen production, photocatalytic decomposition hydrogen production, and water electrolysis hydrogen production. ${ }^{2}$ Electrolysis of water is one promising production method for highefficiency hydrogen evolution reaction (HER). ${ }^{3}$ Typically, electrolysis requires electrocatalysts to participate in the reaction to lower the kinetic energy barrier, thereby reducing the applied driving potential and increasing the reaction rate. ${ }^{4,5}$ Although platinum-based precious metals and their compounds exhibit excellent electrocatalytic HER performance, their high price constraints limit their development and application on an industrial scale. In addition, the typical route for industrial electrolytic hydrogen production is based in alkaline media, which, however, usually requires higher overpotentials than those required for acidic electrolytes due to the relatively slow kinetics caused by an additional water dissociation step. ${ }^{6}$ Therefore, it is highly demanded to develop highly efficient, durable and cost-effective electrocatalysts for industrial scale HER under alkaline conditions.

In recent years, intense efforts have been made in developing effective, long-term durable and earth-abundant metal-based substitutes including carbides, ${ }^{7-12}$ borides,${ }^{13}$ phosphides,${ }^{14-17}$ 
oxides, ${ }^{18-20}$ nitrides,${ }^{21-24}$ chalcogenides ${ }^{25-28}$ and carbon-based materials. ${ }^{9,29}$ Among these candidate materials, transition metal carbides (TMCs) have several advantages, such as high electronic conductivity, noble-metal-like electronic structure for catalysis, broad $\mathrm{pH}$ applicability and chemical stability. ${ }^{30-37}$ As a representative among various TMCs, molybdenum carbides (e.g. $\mathrm{Mo}_{2} \mathrm{C}$ and $\mathrm{MoC}$ ) have been reported to be some of the most active non-precious metal-based electrocatalysts for HER, due to their similar-band electronic configuration to those of Pt-group catalysts. ${ }^{38,39}$ Subsequently, it was found that the introduction of other transition metal elements into the transition metal carbides, using the synergistic effect between different transition metals, can optimize the Gibbs free energy and $\mathrm{M}-\mathrm{H}$ bond energy of hydrogen adsorption ${ }^{40-42}$ and this type of interfacial structure in the material also accelerates the process of water splitting and active hydrogen bonding, all of which contribute to the enhanced hydrogen evolution catalytic performance. ${ }^{43}$ Though polymetallic carbides theoretically have many advantages for achieving improvement in intrinsic catalytic activity for electrocatalysis, few carbides with more than two metal ions for alkaline electrocatalytic HER have been reported. Thus, it is highly demanded to develop high-quality polymetallic carbides for practical hydrogen production.

In this work, we developed a general route to "synthesize" a series of ultrafine Mo-based HER-active bi-/tri-metallic "carbides" as electrocatalysts by "direct" carbonization of multimetal "molybdate" precursors. The unique framework crystal structure of molybdates in the form of $\mathrm{AMoO}_{4}$ offers the capability to construct multi-metal compounds, and the multi-metal components can be adjusted to achieve regulation of the electronic configuration and thereby the catalytic activity. Following this strategy, various bimetallic and trimetallic Mo-based carbides, $\mathrm{Fe}_{3} \mathrm{Mo}_{3} \mathrm{C}, \mathrm{Co}_{6} \mathrm{Mo}_{6} \mathrm{C}_{2}, \mathrm{Mo}_{6} \mathrm{Ni}_{6} \mathrm{C}$, and $\left(\mathrm{Ni}_{x} \mathrm{Co}_{1-x}\right)_{6} \mathrm{Mo}_{6} \mathrm{C}_{2}$, were synthesized. As typical developed examples for HER, a series of ultrafine $\left(\mathrm{Ni}_{x} \mathrm{Co}_{1-x}\right)_{6} \mathrm{Mo}_{6} \mathrm{C}_{2}$ nanocrystals with a small size of $4 \mathrm{~nm}$ was grown by using dicyandiamide (DCA) as a carbon source, resulting in a nano-architectural carbide uniformly embedded in a conductive carbonaceous matrix with high chemical and mechanical stability. With the carbon layer protecting against corrosion and accelerating interfacial charge transfer, the as-prepared series of $\left(\mathrm{Ni}_{x} \mathrm{Co}_{1-x}\right)_{6} \mathrm{Mo}_{6} \mathrm{C}_{2}$ carbides presents effective HER performance, in which the optimized stoichiometric sample $\left(\mathrm{Ni}_{0.2} \mathrm{Co}_{0.8}\right)_{6} \mathrm{Mo}_{6} \mathrm{C}_{2}$ requires an overpotential of $100 \mathrm{mV}$ to drive $10 \mathrm{~mA} \mathrm{~cm}{ }^{-2}$ current density for alkaline HER. Using such an electrocatalyst, a durable current density of $1000 \mathrm{~mA} \mathrm{~cm}{ }^{-2}$ can be achieved by applying an overpotential of $1.84 \mathrm{~V}$ towards HER, which is even lower than the potential required by the $\mathrm{Pt} / \mathrm{C}$ commercial electrocatalyst $(2.12 \mathrm{~V})$ for the same current density, demonstrating its good potential for industrial HER application.

\section{Experimental}

\subsection{Materials}

Ammonium heptamolybdate tetrahydrate $\left(\left(\mathrm{NH}_{4}\right)_{6} \mathrm{Mo}_{7} \mathrm{O}_{24}\right.$. $\left.4 \mathrm{H}_{2} \mathrm{O}\right)$, cobalt nitrate hexahydrate $\left(\mathrm{Co}\left(\mathrm{NO}_{3}\right)_{2} \cdot 6 \mathrm{H}_{2} \mathrm{O}\right)$, nickel nitrate hexahydrate $\left(\mathrm{Ni}\left(\mathrm{NO}_{3}\right)_{2} \cdot 6 \mathrm{H}_{2} \mathrm{O}\right)$, and dicyandiamide (DCA) were purchased from Aladdin Chemical Reagent Co. Ltd. Nafion solution (5 wt\%) was purchased from Alfa Aesar. Commercial platinum on graphitized carbon $(20 \mathrm{wt} \% \mathrm{Pt} / \mathrm{C})$ was purchased from Aldrich. All reagents were used as received without further purification.

\subsection{Synthesis of ultrafine $\left(\mathrm{Ni}_{x} \mathrm{Co}_{1-x}\right)_{6} \mathrm{Mo}_{6} \mathrm{C}_{2}$ nanocrystals}

Aqueous solutions containing $\mathrm{Co}\left(\mathrm{NO}_{3}\right)_{2} \cdot 6 \mathrm{H}_{2} \mathrm{O}, \mathrm{Ni}\left(\mathrm{NO}_{3}\right)_{2} \cdot 6 \mathrm{H}_{2} \mathrm{O}$ and $\left(\mathrm{NH}_{4}\right)_{6} \mathrm{Mo}_{7} \mathrm{O}_{24} \cdot 4 \mathrm{H}_{2} \mathrm{O}$ in a particular ratio were mixed and stirred in a water bath at $80{ }^{\circ} \mathrm{C}$ for $4 \mathrm{~h}$. At the end of the reaction, the resulting light purple $\mathrm{Ni}_{x} \mathrm{Co}_{1-x} \mathrm{MoO}_{4}$ precursor was collected by centrifuging at $3000 \mathrm{rpm}$ and washed several times. Finally, the sample was dried at $80{ }^{\circ} \mathrm{C}$ overnight in a vacuum oven.

$\left(\mathrm{Ni}_{x} \mathrm{Co}_{1-x}\right)_{6} \mathrm{Mo}_{6} \mathrm{C}_{2}$ samples were synthesized by hightemperature carbonization. In a typical procedure, $0.5 \mathrm{~g}$ of dicyandiamide (DCA) was firstly dissolved in $5 \mathrm{~mL}$ of $\mathrm{H}_{2} \mathrm{O}$ at $100{ }^{\circ} \mathrm{C}$ under magnetic stirring to form a transparent solution. Then, $50 \mathrm{mg}$ of $\mathrm{Ni}_{x} \mathrm{Co}_{1-x} \mathrm{MoO}_{4}$ was added to the above hot solution, which was then stirred and boiled until all water evaporated. A dry powder was obtained. Afterwards, the powder was placed in an alumina boat, heated in a pipe furnace at $500{ }^{\circ} \mathrm{C}$ for 30 min under a $\mathrm{N}_{2}$ atmosphere with a heating rate of $2{ }^{\circ} \mathrm{C} \mathrm{min}^{-1}$, and then further heated at $900{ }^{\circ} \mathrm{C}$ for $6 \mathrm{~h}$ with a heating rate of $5{ }^{\circ} \mathrm{C} \mathrm{min}^{-1}$.

\subsection{Synthesis of $\mathrm{Co}_{6} \mathrm{Mo}_{6} \mathrm{C}_{2}$, DCA-Co and DCA-Mo}

$\mathrm{Co}_{6} \mathrm{Mo}_{6} \mathrm{C}_{2}$ was prepared according to the same method as that of $\left(\mathrm{Ni}_{x} \mathrm{Co}_{1-x}\right)_{6} \mathrm{Mo}_{6} \mathrm{C}_{2}$ except that the $\mathrm{Ni}$ element was removed from the precursor. Similarly, DCA-Co or DCA-Mo was prepared according to the same method as that of $\left(\mathrm{Ni}_{x} \mathrm{Co}_{1-x}\right)_{6} \mathrm{Mo}_{6} \mathrm{C}_{2}$ except that the precursor was replaced by $\mathrm{Co}\left(\mathrm{NO}_{3}\right)_{2} \cdot 6 \mathrm{H}_{2} \mathrm{O}$ or $\left(\mathrm{NH}_{4}\right)_{6} \mathrm{Mo}_{7} \mathrm{O}_{24} \cdot 4 \mathrm{H}_{2} \mathrm{O}$.

\subsection{Characterization}

The powder X-ray diffraction (XRD) patterns were recorded using an X-ray diffractometer using $\mathrm{Cu} \mathrm{K} \alpha$ (Dandong TD$3500,30 \mathrm{kV}$ and $20 \mathrm{~mA}$ ). The morphology and microstructures were characterized using scanning electron microscopy (SEM, Hitachi, SU-8010) and high-resolution transmission electron microscopy (TEM/HRTEM, JEM-2100). The surface chemical compositions were studied using X-ray photoelectron spectroscopy (XPS, ESCA Lab MKII).

\subsection{Preparation of the working electrodes}

The catalyst $(5 \mathrm{mg})$ was dispersed in a mixture of water $(0.75 \mathrm{~mL})$ and ethanol $(0.2 \mathrm{~mL})$ containing $5 \%$ Nafion solution $(50 \mu \mathrm{L})$ under ultrasonic irradiation for $c a .1 \mathrm{~h}$ until a homogeneous ink was formed. Then, $5 \mu \mathrm{L}$ of the ink containing $25 \mu \mathrm{g}$ of the catalyst was transferred onto an L-shaped glassy carbon electrode of $3 \mathrm{~mm}$ diameter, yielding a catalyst level of $0.35 \mathrm{mg} \mathrm{cm}^{-2}$. Similarly, $15 \mu \mathrm{L}$ of the ink containing $75 \mu \mathrm{g}$ of the catalyst was transferred onto a glassy carbon disk electrode of $5 \mathrm{~mm}$ diameter, yielding a catalyst level of $0.38 \mathrm{mg} \mathrm{cm}^{-2}$. The electrode with the catalyst was dried at $50{ }^{\circ} \mathrm{C}$ and was used as the working electrode for further electrochemical measurements. 


\subsection{Electrochemical measurement}

The electrochemical performance was tested by using an AUTOLAB PGSTAT302N (Methrohm) via a three-electrode system at room temperature. The reference and counter electrodes were the standard $\mathrm{Hg} / \mathrm{HgO}$ electrode and a carbon rod, respectively. The L-shaped glassy carbon electrode $(d=3 \mathrm{~mm})$ and disk glassy carbon electrode $(d=5 \mathrm{~mm})$ were used as the working electrodes for HER catalysis. Linear sweep voltammetry (LSV) measurements were performed in $1 \mathrm{M} \mathrm{KOH}$. Before HER tests, the electrolyte was deoxygenated with $\mathrm{N}_{2}$ for at least 30 minutes to completely remove oxygen. Electrochemical impedance spectroscopy (EIS) was performed from the frequency of $0.001 \mathrm{~Hz}$ to $10 \mathrm{kHz}$ at the open circuit potential or at other potentials. Long-term stability tests were executed using the chronopotentiometric method at the current densities of 25,125 and $225 \mathrm{~mA} \mathrm{~cm}^{-2}$ for $48 \mathrm{~h}$ and cyclic voltammograms (CVs) recorded at a scan rate of $50 \mathrm{mV} \mathrm{s}^{-1}$ for 2000 times. Furthermore, considering the demands of practical application, chronopotentiometric curves were recorded at large current densities of $1000 \mathrm{~mA} \mathrm{~cm}{ }^{-2}$ for over $48 \mathrm{~h}$. The polarization curves were replotted as overpotential $(\eta) v s$. log current density $(\log j)$, and the Tafel slope $(b)$ was obtained according to the Tafel equation $(\eta=a+b \log (j))$. Potentials were referenced to RHE according to the equation: $E_{\mathrm{RHE}}=0.098 \mathrm{~V}+0.059 \times \mathrm{pH}+$ $E_{\mathrm{Hg} / \mathrm{HgO}}$. Cyclic voltammogram curves were obtained at various scan rates. Electrochemically active surface areas (ECSAs) of the catalysts were determined by electrochemical capacitance measurements with potential ranging from -0.025 to $0.175 \mathrm{~V}$ ( $v s$. RHE) at the scan rates of $10,20,30,50,70$ and $100 \mathrm{mV} \mathrm{s}^{-1}$ to get the electrochemical capacitance. The measured data were plotted as a function of scan rate, and a linear fitting determined the specific capacitance.

\section{Results and discussion}

As schematically illustrated in Fig. 1a, $\mathrm{A}_{m}\left(\mathrm{MoO}_{4}\right)_{n}\left(\mathrm{~A}=\mathrm{Fe}^{3+}, m=2\right.$, and $n=3$; or $\mathrm{A}=\mathrm{Co}^{2+}, \mathrm{Ni}^{2+}$, and $\left(\mathrm{Ni}_{x} \mathrm{Co}_{1-x}\right)^{2+}$, and $\left.m=n=1\right)$, which is a precursor for the preparation of polymetallic compounds, possesses a special molybdate (tetrahedron) crystal structure. The $\mathrm{AMoO}_{4}$ precursor was mixed with DCA by using a solution evaporation method, and then a series of single-phase multi-metal Mo-based carbides $\left(\mathrm{Fe}_{3} \mathrm{Mo}_{3} \mathrm{C}, \mathrm{Mo}_{6} \mathrm{Ni}_{6} \mathrm{C}, \mathrm{Co}_{6} \mathrm{Mo}_{6} \mathrm{C}_{2}\right.$, and $\left.\left(\mathrm{Ni}_{x} \mathrm{Co}_{1-x}\right)_{6} \mathrm{Mo}_{6} \mathrm{C}_{2}\right)$ was obtained through a two step hightemperature carbonization. The chemical compositions and crystal properties of the as-prepared samples were characterized using XRD. As shown in Fig. 1b and Fig. S1 (ESI $\dagger$ ), different cationic Mo-based bimetallic carbides were successfully synthesized, corresponding to $\mathrm{Fe}_{3} \mathrm{Mo}_{3} \mathrm{C}$ (JCPDS No. 47-1191), $\mathrm{Mo}_{6} \mathrm{Ni}_{6} \mathrm{C}$ (JCPDS No. 65-4436) and $\mathrm{Co}_{6} \mathrm{Mo}_{6} \mathrm{C}_{2}$ (JCPDS No. 80-0339), respectively. Specifically, as shown in the XRD pattern of $\left(\mathrm{Ni}_{0.2} \mathrm{Co}_{0.8}\right)_{6} \mathrm{Mo}_{6} \mathrm{C}_{2}$, five distinct characteristic peaks at $35.31^{\circ}$, $39.86^{\circ}, 42.39^{\circ}, 46.37^{\circ}$ and $72.37^{\circ}$ were indexed to the (331), (422), (511), (440) and (822) facets of cubic $\mathrm{Co}_{6} \mathrm{Mo}_{6} \mathrm{C}_{2}(\mathrm{Fd} \overline{3} \mathrm{~m}$ (227), JCPDS No. 80-0339), respectively, which confirmed the presence of the tri-metallic carbide $\left(\mathrm{Ni}_{x} \mathrm{Co}_{1-x}\right)_{6} \mathrm{Mo}_{6} \mathrm{C}_{2}$ with a relatively low $\mathrm{Ni}$ content maintaining a cubic $\mathrm{Co}_{6} \mathrm{Mo}_{6} \mathrm{C}_{2}$ structure. Namely, the addition of Ni does not destroy the structure of the carbides, forming a single-phase multi-metal alloy carbide structure. Meanwhile, the XRD results of DCA-Co, DCA-Mo and $\mathrm{Co}_{6} \mathrm{Mo}_{6} \mathrm{C}_{2}$ indicating the peaks of metallic cobalt (JCPDS No. 15-0806), molybdenum carbide and cubic $\mathrm{Co}_{6} \mathrm{Mo}_{6} \mathrm{C}_{2}$, respectively, are also presented for comparison.

The addition of DCA is regarded to not only act as the carbon source in the final high-temperature carbonization step for crystallization of the carbides, but also as the partitioning and reducing agent for the deoxygenation of the metal molybdate precursors in the first thermal-treatment step, which facilitates the anchoring of intermediate precursors on the carbon-based matrix and the following crystallization without agglomeration.

In view of $\mathrm{Ni}$ - and Co-based compounds being active for HER, for the purpose of developing effective electrocatalysts, the following characterization and discussion take the asprepared $\left(\mathrm{Ni}_{x} \mathrm{Co}_{1-x}\right)_{6} \mathrm{Mo}_{6} \mathrm{C}_{2}$ as examples. The optimized $\left(\mathrm{Ni}_{x}\right.$ $\left.\mathrm{Co}_{1-x}\right)_{6} \mathrm{Mo}_{6} \mathrm{C}_{2}$ catalyst for $\mathrm{HER}$ with a particular ratio of $\mathrm{Ni}$ and

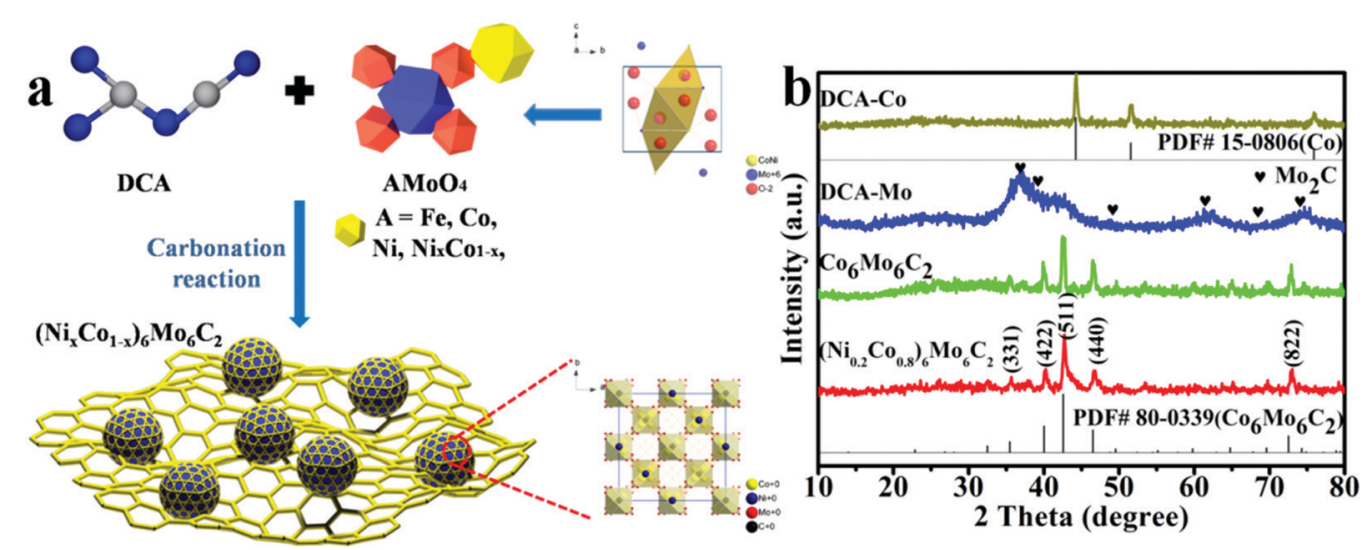

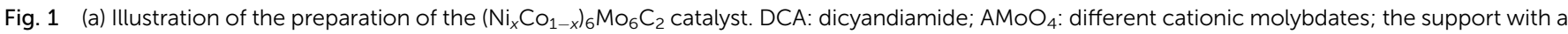

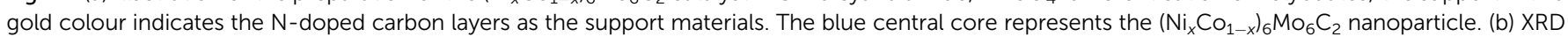
patterns of DCA-Co, DCA-Mo, $\mathrm{CO}_{6} \mathrm{MO}_{6} \mathrm{C}_{2}$ and $\left(\mathrm{Ni}_{0.2} \mathrm{CO}_{0.8}\right)_{6} \mathrm{Mo}_{6} \mathrm{C}_{2}$. 

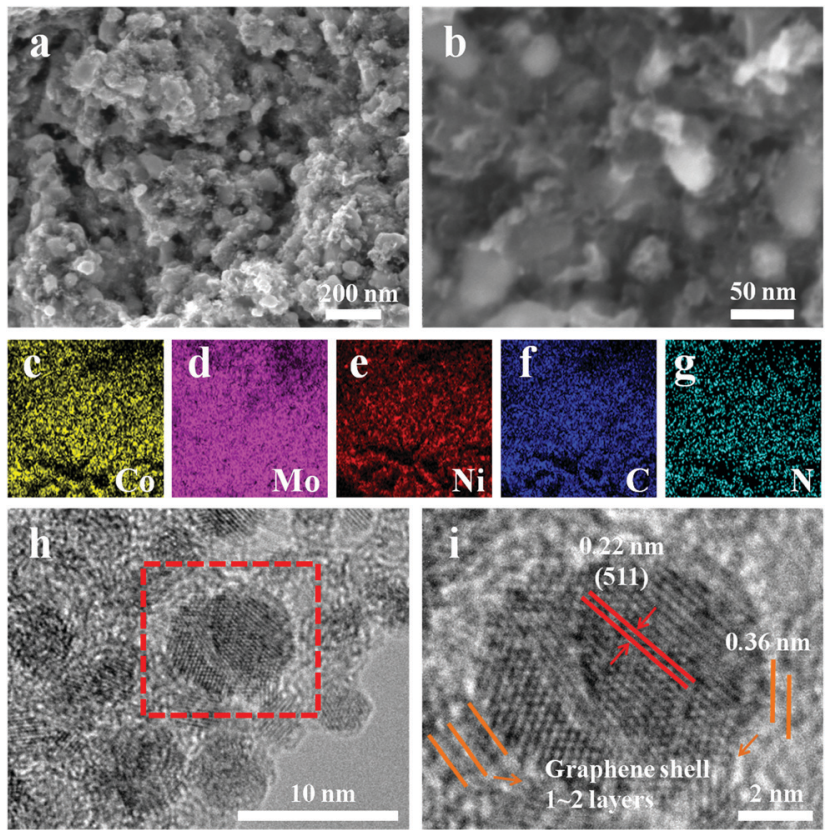

Fig. 2 (a and b) SEM images of $\left(\mathrm{Ni}_{0.2} \mathrm{CO}_{0.8}\right)_{6} \mathrm{Mo}_{6} \mathrm{C}_{2} ;(\mathrm{c}-\mathrm{g})$ elemental mapping of $\mathrm{Co}, \mathrm{Mo}, \mathrm{Ni}, \mathrm{C}$ and $\mathrm{N}$ in $\left(\mathrm{Ni}_{0.2} \mathrm{CO}_{0.8}\right)_{6} \mathrm{Mo}_{6} \mathrm{C}_{2}$; (h) TEM image of $\left(\mathrm{Ni}_{0.2} \mathrm{CO}_{0.8}\right)_{6} \mathrm{Mo}_{6} \mathrm{C}_{2}$; (i) HRTEM image of $\left(\mathrm{Ni}_{0.2} \mathrm{CO}_{0.8}\right)_{6} \mathrm{Mo}_{6} \mathrm{C}_{2}$.

Co could be identified. The microstructure and morphology of $\left(\mathrm{Ni}_{0.2} \mathrm{Co}_{0.8}\right)_{6} \mathrm{Mo}_{6} \mathrm{C}_{2}$ as a representative of the $\left(\mathrm{Ni}_{x} \mathrm{Co}_{1-x}\right)_{6} \mathrm{Mo}_{6} \mathrm{C}_{2}$ series were characterized using scanning electron microscopy (SEM) and transmission electron microscopy (TEM).

As shown in the representative SEM images (Fig. 2a and b), $\left(\mathrm{Ni}_{0.2} \mathrm{Co}_{0.8}\right)_{6} \mathrm{Mo}_{6} \mathrm{C}_{2}$ nanoparticles are uniformly anchored onto a porous carbon matrix. The relevant X-ray energy-dispersive spectroscopy (EDS) elemental mappings (Fig. 2c-g) illustrate that $\mathrm{Co}, \mathrm{Mo}, \mathrm{Ni}, \mathrm{C}$ and $\mathrm{N}$ elements as the components of $\left(\mathrm{Ni}_{0.2} \mathrm{Co}_{0.8}\right)_{6} \mathrm{Mo}_{6} \mathrm{C}_{2}$ nanoparticles are uniformly distributed. The quantified results also confirmed the ratios of the metal elements, which were consistent with the initial amounts used in the reaction (Fig. S2, ESI $\dagger$ ). The TEM image (Fig. 2h) shows that the ultra-small $\left(\mathrm{Ni}_{0.2} \mathrm{Co}_{0.8}\right)_{6} \mathrm{Mo}_{6} \mathrm{C}_{2}$ nanoparticles with an average diameter of $c a .4 .0 \mathrm{~nm}$ are evenly embedded into the N-doped carbon matrix. ${ }^{44,45}$ The successive lattice fringe with a plane distance of $0.22 \mathrm{~nm}$ shown in the high-resolution TEM (HRTEM) image (Fig. 2i) of these particles, which is consistent with the (511) lattice plane of $\mathrm{Co}_{6} \mathrm{Mo}_{6} \mathrm{C}_{2}$, further confirmed the successful growth of single-phase multi-metal carbides. In addition, these nanoparticles are well enveloped by few-layer graphitic carbon shells (with a typical lattice spacing of $0.36 \mathrm{~nm}$ similar to that of graphitic carbon) exhibiting high mechanical and chemical stability. The uniform dispersion of the $\left(\mathrm{Ni}_{0.2} \mathrm{Co}_{0.8}\right)_{6} \mathrm{Mo}_{6} \mathrm{C}_{2}$ nanocrystals with an ultra-small size can be ascribed to the confining effect of the $\mathrm{N}$-doped carbon originating from the carbonization of DCA during the reaction and crystallization of the carbides.

To reveal the chemical state and bonding configuration of the as-prepared $\left(\mathrm{Ni}_{0.2} \mathrm{Co}_{0.8}\right)_{6} \mathrm{Mo}_{6} \mathrm{C}_{2}, \quad \mathrm{X}$-ray photoelectron spectroscopy (XPS) analysis was carried out, as shown in
Fig. 3. The full survey spectrum of $\left(\mathrm{Ni}_{0.2} \mathrm{Co}_{0.8}\right)_{6} \mathrm{Mo}_{6} \mathrm{C}_{2}$ confirmed the existence of peaks in the regions of Ni 2p, Co 2p, Mo 3d, $\mathrm{O}$ 1s, N 1s, and C 1s (Fig. 3a). For the Co 2p XPS spectra (Fig. 3b), the binding energy peaks of Co $2 \mathrm{p}_{3 / 2}$ and Co $2 \mathrm{p}_{1 / 2}$ appear at $781.2 \mathrm{eV}$ and $796.5 \mathrm{eV}$, respectively. The binding energy peaks at $786.2 \mathrm{eV}$ and $803.4 \mathrm{eV}$ are their corresponding satellite structures (S1 and S2), respectively. In addition, slightly weaker metal Co $\left(\mathrm{Co}^{0}\right)$ peaks $(779.5 \mathrm{eV}$ and $794.7 \mathrm{eV})$ of $\left(\mathrm{Ni}_{0.2} \mathrm{Co}_{0.8}\right)_{6-}$ $\mathrm{Mo}_{6} \mathrm{C}_{2}$ could be found, which suggests the formation of cobalt molybdenum bimetallic carbides. ${ }^{46}$ The spectrum of Mo $3 \mathrm{~d}$ (Fig. 3c) implies four valence states $(0,2+, 4+$, and $6+)$ for the catalyst. After a curve deconvolution, the doublets of $232.5 \mathrm{eV} /$ $232.1 \mathrm{eV}$ and $235.5 \mathrm{eV} / 234.9 \mathrm{eV}$ can be attributed to $3 \mathrm{~d}_{3 / 2} / 3 \mathrm{~d}_{5 / 2}$ of $\mathrm{Mo}^{4+}$ and $3 \mathrm{~d}_{3 / 2} / 3 \mathrm{~d}_{5 / 2}$ of $\mathrm{Mo}^{6+}$, which stem from the $\mathrm{MoO}_{2}$ and $\mathrm{MoO}_{3}$ species on the $\left(\mathrm{Ni}_{0.2} \mathrm{Co}_{0.8}\right)_{6} \mathrm{Mo}_{6} \mathrm{C}_{2}$ nanoframe surface. ${ }^{47}$ The peak located at $228.8 \mathrm{eV}$ for Mo $3 \mathrm{~d}_{5 / 2}$ can be ascribed to the $\mathrm{Mo}^{2+}$ species, which is assigned to Mo-C bonding. ${ }^{48}$ The peak located at a binding energy of $227.7 \mathrm{eV}$ is assigned to metallic Mo $\left(\mathrm{Mo}^{0}\right) .{ }^{49}$ The $\mathrm{Mo}^{0}$ species is derived from the metal (Mo)metal bond existing in Mo-based carbides, which has already been proved by previous reports. ${ }^{50}$ For the Ni $2 \mathrm{p}$ spectrum (Fig. 3d), the peaks located at $856.1 \mathrm{eV}$ and $871.4 \mathrm{eV}$ with satellite peaks can be assigned to $\mathrm{Ni}^{2+} 2 \mathrm{p}_{3 / 2}$ and $\mathrm{Ni}^{2+} 2 \mathrm{p}_{1 / 2}$ from $\left(\mathrm{Ni}_{0.2} \mathrm{Co}_{0.8}\right)_{6} \mathrm{Mo}_{6} \mathrm{C}_{2},{ }^{51}$ respectively. The details of the $\mathrm{C} 1 \mathrm{~s}$ XPS spectra are shown in Fig. 3e. The main peak at $284.2 \mathrm{eV}$ corresponds to the $\mathrm{sp}^{2}$ bonded graphite-like carbon, and the peak at $285.2 \mathrm{eV}$ corresponding to $\mathrm{sp}^{3}$ bonded carbon was also observed. It should be noted that there is only a tiny peak at $288.7 \mathrm{eV}$, which is ascribed to $\mathrm{C}=\mathrm{O} / \mathrm{C}-\mathrm{OH}$ groups, indicating that most oxygen containing functional groups of DCA are eliminated during the high temperature treatment and a significant increase in structure ordering of the carbon matrix has been achieved. ${ }^{52}$ The $\mathrm{N}$ 1s spectrum (Fig. 3f) confirmed the $\mathrm{N}$-doping in the carbon matrix including the existence of pyridinic $\mathrm{N}(397.9 \mathrm{eV})$ and pyrrolic $\mathrm{N}(400.2 \mathrm{eV}){ }^{53}$

The electrocatalytic activity of the $\left(\mathrm{Ni}_{x} \mathrm{Co}_{1-x}\right)_{6} \mathrm{Mo}_{6} \mathrm{C}_{2}$ series for HER was systematically evaluated using a standard threeelectrode system in $1 \mathrm{M} \mathrm{KOH}$ electrolyte. For comparison, the performance of counterparts including DCA-Co, DCA-Mo, $\mathrm{Co}_{6} \mathrm{Mo}_{6} \mathrm{C}_{2}$ and a commercial $20 \% \mathrm{Pt} / \mathrm{C}$ catalyst was also studied in parallel. The polarization curves in Fig. 4a and Fig. S3 (ESI $\dagger$ ) reveal that the $\mathrm{Ni} / \mathrm{Co} / \mathrm{Mo}$ ternary carbides $\left(\mathrm{Ni}_{x} \mathrm{Co}_{1-x}\right)_{6} \mathrm{Mo}_{6} \mathrm{C}_{2}$ possess better electrocatalytic activities towards the HER in comparison to their binary and mono metal carbide counterparts, and $\left(\mathrm{Ni}_{0.2} \mathrm{Co}_{0.8}\right)_{6} \mathrm{Mo}_{6} \mathrm{C}_{2}$ exhibits the highest activity among the $\left(\mathrm{Ni}_{x} \mathrm{Co}_{1-x}\right)_{6} \mathrm{Mo}_{6} \mathrm{C}_{2}$ series. To achieve the current density of $10 \mathrm{~mA} \mathrm{~cm} \mathrm{~cm}^{-2}$, as shown in the inset of Fig. 4a, $\left(\mathrm{Ni}_{0.2} \mathrm{Co}_{0.8}\right)_{6} \mathrm{Mo}_{6} \mathrm{C}_{2}$ needs an overpotential of $100 \mathrm{mV}$, which is smaller than those of $\mathrm{Co}_{6} \mathrm{Mo}_{6} \mathrm{C}_{2}(152 \mathrm{mV})$, DCA-Mo $(174 \mathrm{mV})$ and DCA-Co (245 $\mathrm{mV})$.

In view of practical hydrogen production at an industrial scale, a current density with a higher order of magnitude is usually required for electrolysis operation. Therefore, to probe the potential of the as-prepared ternary carbides for practical applications, the HER activities at a higher current (such as $1000 \mathrm{~mA} \mathrm{~cm}{ }^{-2}$ ) of these samples were also evaluated. The 

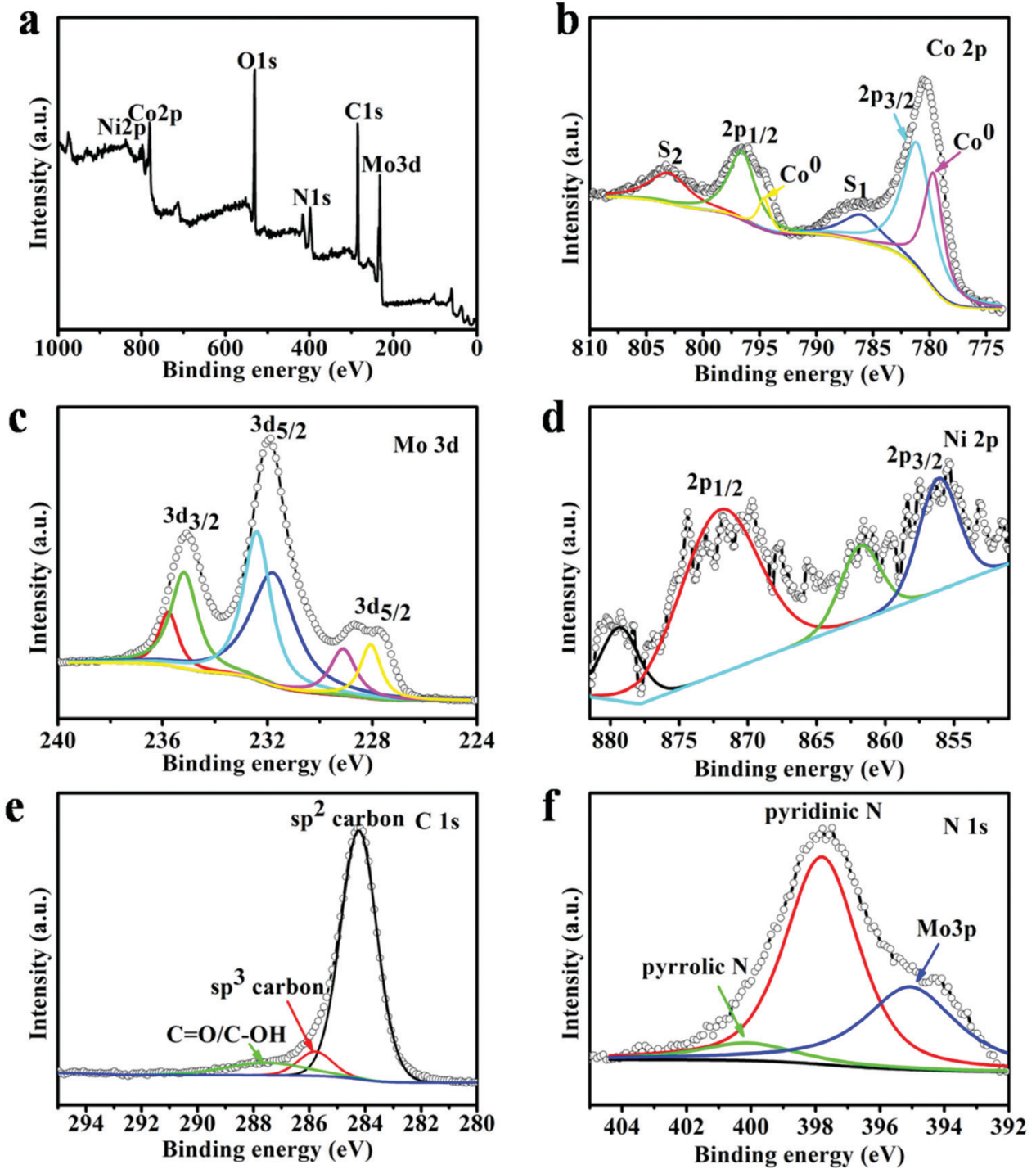

Fig. 3 (a) XPS spectrum of $\left(\mathrm{Ni}_{0.2} \mathrm{CO}_{0.8}\right)_{6} \mathrm{Mo}_{6} \mathrm{C}_{2}$, high resolution XPS spectra and the fitted data of Co $2 \mathrm{p}$ (b), Mo 3d (c), Ni 2p (d), C 1s (e) and N 1s (f) of $\left(\mathrm{Ni}_{0.2} \mathrm{CO}_{0.8}\right)_{6} \mathrm{MO}_{6} \mathrm{C}_{2}$.

overpotential required for the current density of $1000 \mathrm{~mA} \mathrm{~cm}{ }^{-2}$ using the $\left(\mathrm{Ni}_{0.2} \mathrm{Co}_{0.8}\right)_{6} \mathrm{Mo}_{6} \mathrm{C}_{2}$ electrocatalyst is only $1.84 \mathrm{~V}$, which is superior to other carbide counterparts in this work and even better than the performance of the commercial $\mathrm{Pt} / \mathrm{C}$ $(20 \% \mathrm{Pt})$ catalyst $\left(2.12 \mathrm{~V}\right.$ required for $\left.1000 \mathrm{~mA} \mathrm{~cm}{ }^{-2}\right)$. It should be noted that although the activity of commercial Pt/C at a low potential $\left(29 \mathrm{mV}\right.$ required for $\left.10 \mathrm{~mA} \mathrm{~cm}^{-2}\right)$ is better than that of $\left(\mathrm{Ni}_{0.2} \mathrm{Co}_{0.8}\right)_{6} \mathrm{Mo}_{6} \mathrm{C}_{2},\left(\mathrm{Ni}_{0.2} \mathrm{Co}_{0.8}\right)_{6} \mathrm{Mo}_{6} \mathrm{C}_{2}$ can drive a higher current density when applying a potential over $745 \mathrm{mV}$. These results suggest that $\left(\mathrm{Ni}_{0.2} \mathrm{Co}_{0.8}\right)_{6} \mathrm{Mo}_{6} \mathrm{C}_{2}$ has great potential for practical HER applications.

The Tafel plots were derived from the HER polarization curves by deriving the logarithm of the current density, according to the following equation: $\eta=a+b \log j$, where $\eta$ is the overpotential $\left(\eta_{10}\right), b$ is the Tafel slope, and $j$ is the current density. The equation is usually used to evaluate the reaction kinetics in the electrocatalytic hydrogen generation process. ${ }^{54}$
Hydronium ion reduction consists of three steps: the Volmer, Heyrvosky and Tafel steps, respectively.

Electrochemical hydrogen adsorption (Volmer step)

$$
\mathrm{H}_{2} \mathrm{O}+\mathrm{M}+\mathrm{e}^{-} \rightarrow \mathrm{M}-\mathrm{H}^{*}+\mathrm{OH}^{-}
$$

Electrochemical desorption (Heyrvosky step)

$$
\mathrm{M}-\mathrm{H}^{*}+\mathrm{H}_{2} \mathrm{O}+\mathrm{e}^{-} \rightarrow \mathrm{M}+\mathrm{OH}^{-}+\mathrm{H}_{2}
$$

Chemical desorption (Tafel step)

$$
2 \mathrm{M}-\mathrm{H}^{*} \rightarrow 2 \mathrm{M}+\mathrm{H} 2
$$

where $\mathrm{H}^{*}$ designates a hydrogen atom chemically adsorbed on an active site of the electrode surface $(\mathrm{M}) .^{5,56}$

The Tafel slope is regarded as an intrinsic parameter to reveal the rate determining step in the kinetics of HER. Fig. 4b demonstrates that the Tafel slope of the $\left(\mathrm{Ni}_{0.2} \mathrm{Co}_{0.8}\right)_{6} \mathrm{Mo}_{6} \mathrm{C}_{2}$ catalyst is about $59 \mathrm{mV} \mathrm{dec}^{-1}$, while the Tafel slopes of DCA- 

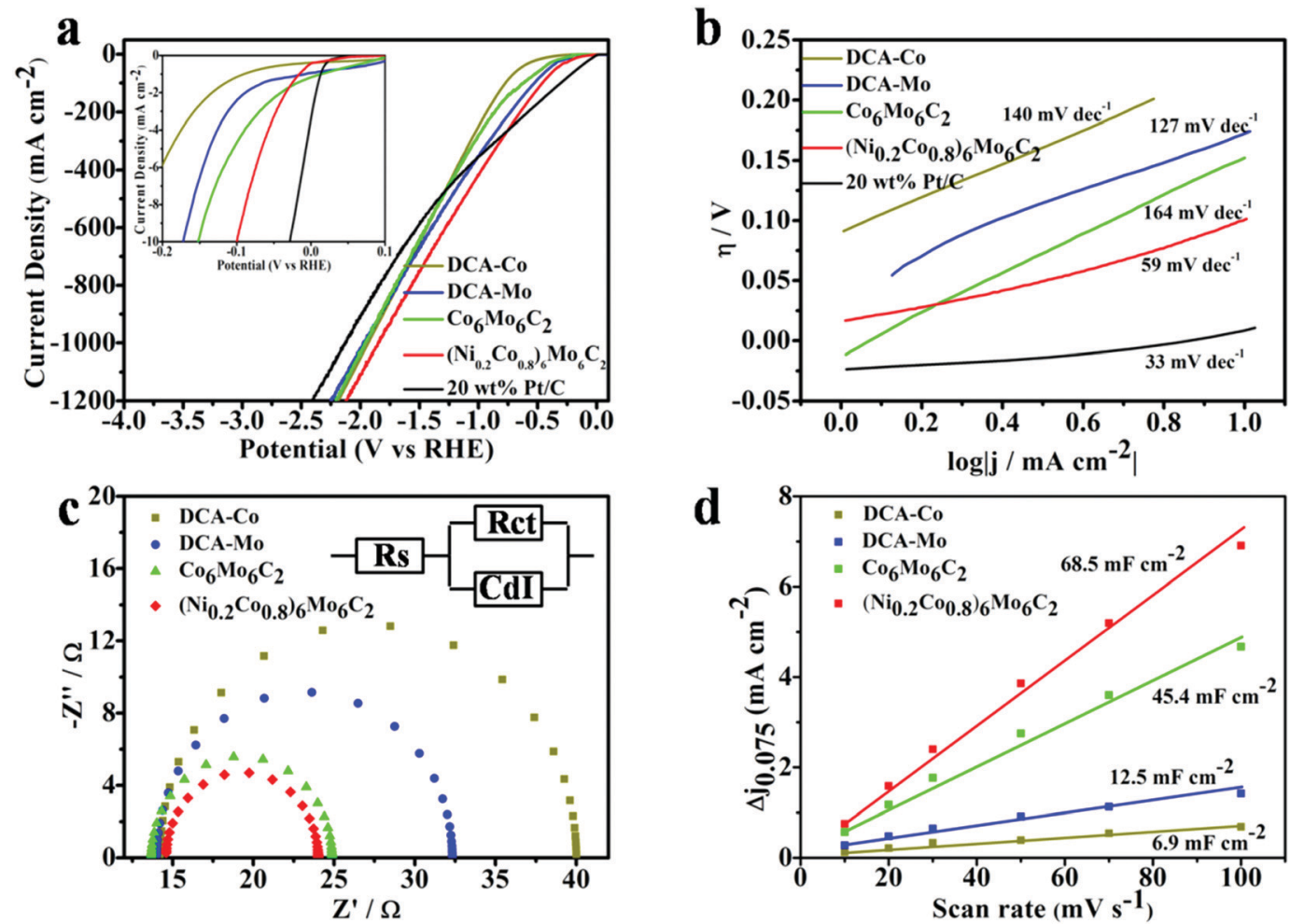

Fig. 4 (a) Polarization curves of $\left(\mathrm{Ni}_{0.2} \mathrm{CO}_{0.8}\right)_{6} \mathrm{Mo}_{6} \mathrm{C}_{2}, \mathrm{Co}_{6} \mathrm{Mo}_{6} \mathrm{C}_{2}, \mathrm{DCA}-\mathrm{Mo}, \mathrm{DCA}-\mathrm{Co}$ and $\mathrm{Pt} / \mathrm{C}$ on a glassy carbon disk electrode in $1 \mathrm{M}$ KOH. Inset: Polarization curves of the same catalyst on an L-shaped glassy carbon electrode in the range of $0-10 \mathrm{~mA} \mathrm{~cm}^{-2}$ current density; (b) Tafel plots of $\left(\mathrm{Ni}_{0.2} \mathrm{CO}_{0.8}\right)_{6} \mathrm{MO}_{6} \mathrm{C}_{2}, \mathrm{CO}_{6} \mathrm{MO}_{6} \mathrm{C}_{2}, \mathrm{DCA}-\mathrm{Mo}$, DCA-Co and Pt/C in $1 \mathrm{M} \mathrm{KOH}$; (c) Nyquist plots of electrochemical impedance spectroscopy (EIS) of $\left(\mathrm{Ni}_{0.2} \mathrm{CO}_{0.8}\right)_{6} \mathrm{Mo}_{6} \mathrm{C}_{2}, \mathrm{CO}_{6} \mathrm{Mo}_{6} \mathrm{C}_{2}, \mathrm{DCA}-\mathrm{Mo}$ and $\mathrm{DCA}-\mathrm{Co}$ in $1 \mathrm{M} \mathrm{KOH}$; (d) the capacitive current at $0.075 \mathrm{~V}$ as a function of scan rate for $\left(\mathrm{Ni}_{0.2} \mathrm{CO}_{0.8}\right)_{6} \mathrm{Mo}_{6} \mathrm{C}_{2}$, $\mathrm{Co}_{6} \mathrm{Mo}_{6} \mathrm{C}_{2}$, DCA-Mo and DCA-Co in $1 \mathrm{M} \mathrm{KOH}$.

Co, DCA-Mo and $\mathrm{Co}_{6} \mathrm{Mo}_{6} \mathrm{C}_{2}$ are 140,127 and $164 \mathrm{mV} \mathrm{dec}{ }^{-1}$, respectively. Thus, the Volmer-Heyrovsky mechanism is presumed to dominate the HER process when using $\left(\mathrm{Ni}_{0.2} \mathrm{Co}_{0.8}\right)_{6-}$ $\mathrm{Mo}_{6} \mathrm{C}_{2}$ as the catalyst, and the hydrogen generation rate could be increased rapidly by applying a higher overpotential, resulting in high HER activity with high voltages applied. ${ }^{57,58}$ To better understand the role of the interface reaction and electrode kinetics for HER, EIS analysis was further employed. ${ }^{59}$ As the Nyquist plots show in Fig. 4c, the charge transfer resistance $R_{\text {ct }}$ of DCA-Co, DCA-Mo, $\mathrm{Co}_{6} \mathrm{Mo}_{6} \mathrm{C}_{2}$, and $\left(\mathrm{Ni}_{0.2} \mathrm{Co}_{0.8}\right)_{6} \mathrm{Mo}_{6} \mathrm{C}_{2}$ is $R_{\mathrm{ct}}=25.8 \Omega, 18.0 \Omega, 11.2 \Omega$, and $9.42 \Omega$, respectively. Compared with the other catalysts, $\left(\mathrm{Ni}_{0.2} \mathrm{Co}_{0.8}\right)_{6} \mathrm{Mo}_{6} \mathrm{C}_{2}$ displays a much lower $R_{\mathrm{ct}}$, indicating that the addition of Co and especially Ni in the multi-metal carbides significantly enhances the transfer rate of carriers and the faradaic process. ${ }^{60}$ It is generally believed that the electric double layer capacitance $\left(C_{\mathrm{dl}}\right)$ is directly proportional to the electrochemically active surface area (ECSA) during the electrocatalytic process. When there are more effective active components on the catalyst surface, the larger the ECSA, the better the corresponding catalytic activity, so the electric double layer capacitance can often be used to determine the catalyst activity. ${ }^{61}$ Thus, the CVs of these samples were recorded in the potential range not containing the redox states at different scan rates $(10,20,30$, 50, 70 and $100 \mathrm{mV} \mathrm{s}^{-1}$ ) in $1 \mathrm{M} \mathrm{KOH}$. As shown in Fig. 4d and Fig. S4 (ESI $\dagger)$, one can clearly observe that the $C_{\mathrm{dl}}$ of
$\left(\mathrm{Ni}_{0.2} \mathrm{Co}_{0.8}\right)_{6} \mathrm{Mo}_{6} \mathrm{C}_{2}, \mathrm{Co}_{6} \mathrm{Mo}_{6} \mathrm{C}_{2}$, DCA-Mo and DCA-Co is 68.5, 45.4, 12.5 and $6.9 \mathrm{mF} \mathrm{cm}^{-2}$, respectively, manifesting that the $C_{\mathrm{dl}}$ of $\left(\mathrm{Ni}_{0.2} \mathrm{Co}_{0.8}\right)_{6} \mathrm{Mo}_{6} \mathrm{C}_{2}$ is the highest, which implies that the multi-metal synergy helps the carbides in exposing more accessible electrochemically active sites.

The catalytic stability is another critical criterion for determining practical HER capability. As shown in Fig. 5a, the stability of the as-prepared $\left(\mathrm{Ni}_{0.2} \mathrm{Co}_{0.8}\right)_{6} \mathrm{Mo}_{6} \mathrm{C}_{2}$ was evaluated by a cycling electrochemical test in the form of cyclic voltammetry (CV) sweeps between $0.02 \mathrm{~V}$-and $-0.25 \mathrm{~V} v$ s. RHE at a scan rate of $50 \mathrm{mV} \mathrm{s}^{-1}$ in $1 \mathrm{M} \mathrm{KOH}$. The negligible change between the polarization curves obtained before and after 2000 continuous $\mathrm{CV}$ tests demonstrates the superior stability of $\left(\mathrm{Ni}_{0.2} \mathrm{Co}_{0.8}\right)_{6} \mathrm{Mo}_{6} \mathrm{C}_{2}$ in electrochemical processes. The HER durability at a high current density of $\left(\mathrm{Ni}_{0.2} \mathrm{Co}_{0.8}\right)_{6} \mathrm{Mo}_{6} \mathrm{C}_{2}$ was also studied by carrying out long-term chronopotentiometry. Only a slight catalytic current depression can be observed after the long-term electrolysis operated at different constant potentials $(160 \mathrm{mV}, 470 \mathrm{mV}$, and $650 \mathrm{mV}$ ) over 48 hours (Fig. 5b), illustrating the remarkable stability of such ternary carbide catalysts in the alkaline HER process. In comparison, the electrolysis current density driven by the commercial $\mathrm{Pt} / \mathrm{C}$ catalyst at $650 \mathrm{mV}$ constant potential attenuates by $40 \%$ after 15 hours. In addition, considering the demands of practical application, chronopotentiometric curves were recorded for the $\left(\mathrm{Ni}_{0.2} \mathrm{Co}_{0.8}\right)_{6} \mathrm{Mo}_{6} \mathrm{C}_{2}$ catalyst by driving a long-term high current density of $1000 \mathrm{~mA} \mathrm{~cm}^{-2}$. As shown in 

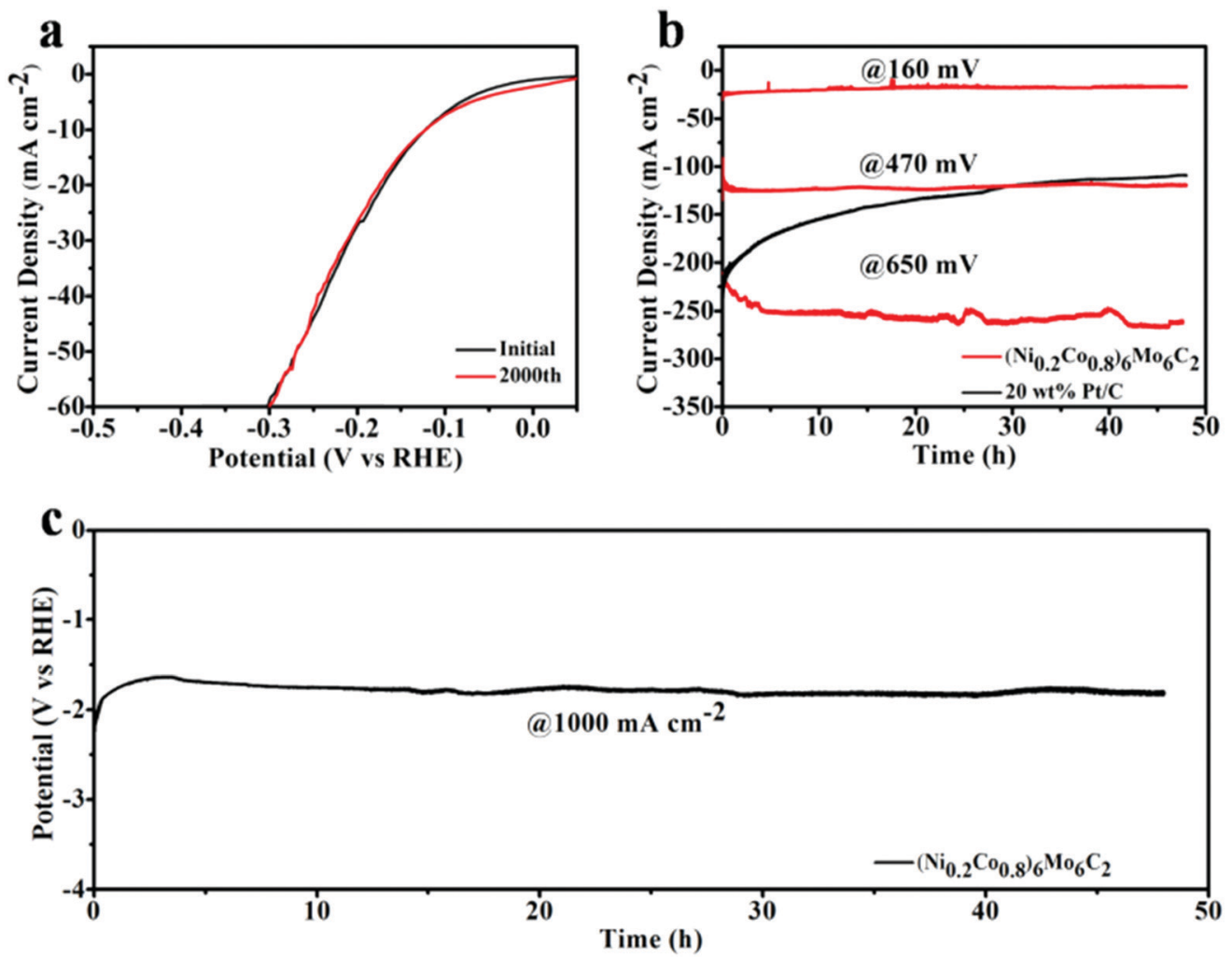

Fig. 5 (a) Polarization curves of $\left(\mathrm{Ni}_{0.2} \mathrm{CO}_{0.8}\right)_{6} \mathrm{MO}_{6} \mathrm{C}_{2}$ initially and after 2000 cycles in $1 \mathrm{M} \mathrm{KOH}$; (b) chronoamperometric responses of $\left(\mathrm{Ni}_{0.2} \mathrm{CO}_{0.8}\right)_{6} \mathrm{MO}_{6} \mathrm{C}_{2}$ and Pt/C at different static over-potentials for $48 \mathrm{~h}$; (c) chronopotentiometric curves at a constant current density of $1000 \mathrm{~mA} \mathrm{~cm}{ }^{-2} \mathrm{for} 48 \mathrm{~h}$.

Fig. $5 \mathrm{c}$, the potential required for maintaining $1000 \mathrm{~mA} \mathrm{~cm}^{-2}$ remains reasonably stable and lasts over $48 \mathrm{~h}$, suggesting the great potential of the as-prepared $\left(\mathrm{Ni}_{0.2} \mathrm{Co}_{0.8}\right)_{6} \mathrm{Mo}_{6} \mathrm{C}_{2}$ for commercial HER utilization. The TEM and XPS characterization results (Fig. S6 and S7, ESI $\dagger$ ) of the catalyst after the long-time constant-current HER process demonstrate that the structure and composition of $\left(\mathrm{Ni}_{0.2} \mathrm{Co}_{0.8}\right)_{6} \mathrm{Mo}_{6} \mathrm{C}_{2}$ are not obviously changed, showing the good stability of such materials.

Based on the experimental results obtained in this work, it is clear that the synergistic effect between different transition metals in the carbides can optimize the Gibbs free energy and bonding energy of hydrogen adsorption, which then affects the process of water splitting and HER performance. Compared to DCA-Co and DCA-Mo, the $\mathrm{Co}_{6} \mathrm{Mo}_{6} \mathrm{C}_{2}$ carbides obtained by mixing $\mathrm{Co}$ and Mo exhibit improved HER activity. By including $\mathrm{Ni}$ in the crystal structure of $\mathrm{Co}_{6} \mathrm{Mo}_{6} \mathrm{C}_{2}$, the electrocatalytic activity of the multi-metal carbides is further enhanced. The active sites for HER in $\left(\mathrm{Ni}_{0.2} \mathrm{Co}_{0.8}\right)_{6} \mathrm{Mo}_{6} \mathrm{C}_{2}$ are significantly increased in relation to the single metal carbides, which can be confirmed by the analysis of the electrochemically active surface areas of different samples. The superior HER activity and durability of $\left(\mathrm{Ni}_{0.2} \mathrm{Co}_{0.8}\right)_{6} \mathrm{Mo}_{6} \mathrm{C}_{2}$ in alkaline media can be concluded as due to the synergistic effects of the multi-metal coordinated carbides and the carbon-based architectures. In detail, the following aspects could be outlined: (1) first of all, the small size of $\left(\mathrm{Ni}_{0.2} \mathrm{Co}_{0.8}\right)_{6} \mathrm{Mo}_{6} \mathrm{C}_{2}$ ensures a large amount of exposed active sites; (2) double metal cations (Co and $\mathrm{Ni}$ ) introduce multi-metal synergy to assist fast water dissociation to yield a sufficient amount of protons to accelerate the hydrogen production; (3) the carbon matrix and protective layer derived from DCA offer good chemical and mechanical stability, as well as high interfacial conductivity for the electrocatalysts.

\section{Conclusions}

In summary, we reported a simple and novel strategy to synthesize multi-metal carbide nanoparticles covered by fewlayer $\mathrm{N}$-doped graphitic carbon shells, which were in situ prepared by a two-step method from $\mathrm{Ni}_{x} \mathrm{Co}_{1-x} \mathrm{MoO}_{4}$ and DCA in a $\mathrm{N}_{2}$ atmosphere. This $\left(\mathrm{Ni}_{x} \mathrm{Co}_{1-x}\right)_{6} \mathrm{Mo}_{6} \mathrm{C}_{2}$ series of materials, especially $\left(\mathrm{Ni}_{0.2} \mathrm{Co}_{0.8}\right)_{6} \mathrm{Mo}_{6} \mathrm{C}_{2}$, shows good HER performance and high long-term stability in alkaline solution even at a large current density. The superior HER activity can be attributed to the cooperative/synergistic effects of the nanosized multimetallic carbides $\left(\mathrm{Ni}_{x} \mathrm{Co}_{1-x}\right)_{6} \mathrm{Mo}_{6} \mathrm{C}_{2}$ and the carbon-based protective support. The novelty of this work is not only the fundamental understanding and scientific discovery of new nanomaterials, but also their readiness for large-scale production and industrial application.

\section{Conflicts of interest}

There are no conflicts to declare. 


\section{Acknowledgements}

This work is supported by the National Natural Science Foundation of China (No. 11704007), Baoji University of Arts and Sciences Key Research (Grant No. ZK16070), the Provincial Natural Science Foundation of Hunan (No. 2019JJ50602), and the Scientific Research Fund of Hunan Provincial Education Department (No. 18C0105).

\section{References}

1 B. Dunn, H. Kamath and J. M. Tarascon, Science, 2011, 334, 928-935.

2 X. X. Zou and Y. Zhang, Chem. Soc. Rev., 2015, 44, 5148-5180.

3 X. F. Lu, L. Yu and X. W. Lou, Sci. Adv., 2019, 5, eaav6009.

4 W. F. Chen, J. T. Muckerman and E. Fujita, Chem. Commun., 2013, 49, 8896-8909.

5 J. Li and D. Zheng, Adv. Sci., 2017, 4, 1600380.

6 Z. W. Seh, J. Kibsgaard, C. F. Dickens, I. B. Chorkendorff, J. K. Nørskov and T. F. Jaramillo, Science, 2017, 355, eaad4998.

7 J. S. Li, Y. Wang, C. H. Liu, S. L. Li, Y. G. Wang, L. Z. Dong, Z. H. Dai, Y. F. Li and Y. Q. Lan, Nat. Commun., 2016, 7, 11204-11211.

8 R. G. Ma, Y. Zhou, Y. F. Chen, P. X. Li, Q. Liu and J. C. Wang, Angew. Chem., Int. Ed., 2015, 54, 14723-14727.

9 Y. P. Liu, G. T. Yu, G. D. Li, Y. H. Sun, T. Asefa, W. Chen and X. X. Zou, Angew. Chem., Int. Ed., 2015, 54, 10752-10757.

10 Y. Huang, Q. F. Gong, X. N. Song, K. Feng, K. Q. Nie, F. P. Zhao, Y. Y. Wang, M. Zeng, J. Zhong and Y. G. Li, ACS Nano, 2016, 10, 11337-11343.

11 M. Qamar, A. Adam, B. Merzougui, A. Helal, O. Abdulhamid and M. N. Siddiqui, J. Mater. Chem. A, 2016, 4, 16225-16232.

12 F. X. Ma, H. B. Wu, B. Y. Xia, C. Y. Xu and X. W. Lou, Angew. Chem., Int. Ed., 2015, 54, 15395-15399.

$13 \mathrm{H}$. Vrubel and X. Hu, Angew. Chem., Int. Ed., 2012, 51, $12703 \mathrm{e} 6$.

14 J. Q. Tian, Q. Liu, A. M. Asiri and X. P. Sun, J. Am. Chem. Soc., 2014, 136, 7587-7590.

15 L. Jiao, Y. X. Zhou and H. L. Jiang, Chem. Sci., 2016, 7, 1690-1695.

16 Y. Zhang, H. J. Zhang, Y. Y. Feng, L. Liu and Y. Wang, ACS Appl. Mater. Interfaces, 2015, 7, 26684-26690.

17 H. J. Yan, Y. Q. Jiao, A. P. Wu, C. G. Tian, X. M. Zhang, M. Wang, Z. Y. Ren and H. G. Fu, Chem. Commun., 2016, 52, 9530-9533.

18 Z. H. Xiao, Y. Wang, Y. C. Huang, Z. X. Wei, C. L. Dong and J. M. Ma, Energy Environ. Sci., 2013, 10(12), 2563-2569.

19 J. Yin, P. P. Zhou, L. An, L. Huang, C. W. Shao, J. Wang, H. Y. Liu and P. X. Xi, Nanoscale, 2016, 8, 1390.

20 H. H. Shi, H. F. Liang, F. W. Ming and Z. C. Wang, Angew. Chem., Int. Ed., 2017, 56, 573.

21 H. J. Yan, C. G. Tian, L. Wang, A. P. Wu, M. C. Meng, L. Zhao and H. G. Fu, Angew. Chem., Int. Ed., 2015, 54, 6325-6329.

22 Y. Zhao, K. Kamiya, K. Hashimoto and S. Nakanishi, J. Am. Chem. Soc., 2015, 137, 110-113.
23 J. F. Xie, S. Li, X. D. Zhang, J. J. Zhang, R. X. Wang, H. Zhang, B. C. Pan and Y. Xie, Chem. Sci., 2014, 5, 4615-4620.

24 W. F. Chen, J. M. Schneider, K. Sasaki, C. H. Wang, J. Schneider, S. Iyer, Y. M. Zhu, J. T. Muckerman and E. Fujita, ChemSusChem, 2014, 7, 2414-2418.

25 L. L. Feng, G. T. Yu, Y. Y. Wu, G. D. Li, H. Li, Y. Sun, H. Asefa, T. W. Chen and X. X. Zou, J. Am. Chem. Soc., 2015, 137, 14023-14026.

26 T. Y. Wang, L. Liu, Z. W. Zhu, P. Papakonstantinou, J. B. Hu, H. Y. Liu and M. X. Li, Energy Environ. Sci., 2013, 6, 625-633.

27 K. Zhang, H. J. Kim, J. T. Lee, G. W. Chang, X. J. Shi, W. J. Kim, M. Ma, K. J. Kong, J. M. Choi, M. S. Song and J. H. Park, ChemSusChem, 2014, 7, 2489-2495.

28 S. F. Zhuo, Y. Xu, W. W. Zhao, J. Zhang and B. Zhang, Angew. Chem., Int. Ed., 2013, 52, 8602-8606.

29 H. Vrubel and X. I. Hu, Angew. Chem., Int. Ed., 2012, 51, 12703-12706.

30 Y. Liu, T. G. Kelly, J. G. Chen and W. E. Mustain, ACS Catal., 2013, 3, 1184-1194.

31 M. Miao, J. Pan, T. He, Y. Yan, B. Y. Xia and X. Wang, Chem. - Eur. J., 2017, 23, 10947-10961.

32 Y. C. Kimmel, X. Xu, W. Yu, X. Yang and J. G. Chen, ACS Catal., 2014, 4, 1558-1562.

33 D. Vikraman, S. Hussain, K. Karuppasamy, A. Feroze, A. Kathalingam and A. Sanmugam, Appl. Catal., B, 2020, 264, 118531.

34 S. Hussain, I. Rabani, D. Vikraman, A. Feroze and K. Karuppasamy, ACS Sustainable Chem. Eng., 2020, 32, 12248-12259.

35 D. Vikraman, K. Akbar, S. Hussain, G. Yoo, J. Y. Jang and S. H. Chun, Nano Energy, 2017, 35, 101-114.

36 D. Vikraman, H. G. Abbas, S. Hussain, K. Akbar and K. Karuppasamy, ACS Sustainable Chem. Eng., 2019, 7, 458-469.

37 S. Hussain, I. Rabani, D. Vikraman, A. Feroze, M. Ali, Y. S. Seo, H. S. Kim and S. H. Chun, Nanomaterials, 2020, 10, 1597.

38 C. Wan, Y. N. Regmi and B. M. Leonard, Angew. Chem., Int. Ed., 2014, 53, 6407-6410.

39 H. Ang, H. T. Tan, Z. M. Luo, Y. Zhang, Y. Y. Guo, G. Guo, H. Zhang and Q. Yan, Small, 2015, 11, 6278-6284.

40 G. Wu, C. M. Johnston and N. H. Mack, J. Mater. Chem., 2011, 21, 11392-11405.

41 S. Bukola, B. Merzougui and A. Akinpelu, Electrochim. Acta, 2016, 190, 1113-1123.

42 Y. Zhao, K. Kamiya and K. Hashimoto, Angew. Chem., Int. Ed., 2013, 52, 13638-13641.

43 D. V. Esposito, S. T. Hunt and Y. C. Kimmel, J. Am. Chem. Soc., 2012, 134, 3025-3033.

44 Y. P. Liu, G. T. Yu, G. D. Li, Y. H. Sun, T. Asefa, W. Chen and X. X. Zou, Angew. Chem., Int. Ed., 2015, 54, 10752-10757.

45 Y. T. Xu, X. F. Xiao, Z. M. Ye, S. L. Zhao, R. A. Shen, C. T. He, J. P. Zhang, Y. D. Li and X. M. Chen, J. Am. Chem. Soc., 2017, 139, 5285-5288.

46 X. Ma, H. Meng, M. Cai and P. K. Shen, J. Am. Chem. Soc., 2012, 134, 1954-1957. 
47 L. F. Pan, Y. H. Li, S. Yang, P. F. Liu, M. Q. Yu and H. G. Yang, Chem. Commun., 2014, 50, 13135-13137.

48 C. Shi, A. Zhang, X. Li, S. Zhang, A. Zhu, Y. Ma and C. Au, Appl. Catal., A, 2012, 431, 164-170.

49 Y. Liu, G. Yu, G. D. Li, Y. Sun, T. Asefa, W. Chen and X. Zou, Angew. Chem., Int. Ed., 2015, 54, 10752-10757.

50 M. Y. Zu, P. F. Liu, C. Wang, Y. Wang, L. R. Zheng, B. Zhang, H. Zhao and H. G. Yang, ACS Energy Lett., 2018, 3, 78-84.

51 H. Liu, Q. He, H. Jiang, Y. Lin, Y. Zhang, M. Habib, S. Chen and L. Song, ACS Nano, 2017, 11, 11574-11583.

52 C. He, S. P. Jiang and P. K. Shen, Sci. Rep., 2013, 3, 2144.

53 Y. Zheng, Y. Jiao, L. H. Li, T. Xing, Y. Chen, M. Jaroniec and S. Z. Qiao, ACS Nano, 2014, 8, 5290-5296.

54 Y. Y. Chen, Y. Zhang, W. J. Jiang, X. Zhang, Z. H. Dai, L. J. Wan and J. S. Hu, ACS Nano, 2016, 10, 8851-8860.
55 M. G. de Chialvo and A. C. Chialvo, J. Electrochem. Soc., 2000, 147, 1619-1622.

56 B. E. Conway and L. J. Bai, J. Electroanal. Chem. Interfacial Electrochem., 1986, 198, 149-175.

57 B. E. Conway and B. V. Tilak, Advances in catalysis, Academic Press, 1992, vol. 38, pp. 1-147.

58 S. A. Vilekar, I. Fishtik and R. Datta, J. Electrochem. Soc., 2010, 157, B1040-B1050.

59 R. G. Ma, Y. Zhou, Y. F. Chen, P. X. Li, Q. Liu and J. C. Wang, Angew. Chem., Int. Ed., 2015, 54, 14723-14727.

60 Y. Yin, J. C. Han, Y. M. Zhang, X. H. Zhang, P. Xu, Q. Yuan, L. Samad, X. J. Wang, Y. Wang, Z. H. Zhang, P. Zhang, X. Z. Cao, B. Song and S. Jin, J. Am. Chem. Soc., 2016, 138, 7965-7972.

61 J. F. Xie, S. Li, X. D. Zhang, J. J. Zhang, R. X. Wang, H. Zhang, B. C. Pan and Y. Xie, Chem. Sci., 2014, 5, 4615. 